\title{
Entrevista a Pablo Lapegna ${ }^{1}$
}

Pablo Lapegna es profesor asociado de Sociología y Estudios Latinoamericanos y Caribeños en la Universidad de Georgia, EE.UU. Es licenciado en Sociología por la Universidad de Buenos Aires y obtuvo su PhD en Sociología en la Universidad Estatal de Nueva York (Stony Brook). Con un enfoque en América Latina y en métodos cualitativos, LaPegna investiga y enseña sobre estudios agrarios críticos y procesos globales, sociología política, y movimientos sociales. En esta entrevista, Maritza Paredes ${ }^{2}$ conversa con él sobre su nuevo libro La Argentina transgénica. De la resistencia a la adaptación, una etnografia de las poblaciones campesinas (Siglo XXI editores) que investiga la expansión de la soja genéticamente modificada en Argentina y las formas en que las poblaciones rurales piensan, sienten y actúan frente a ella cuando se ven afectadas por problemas ambientales y dificultades cotidianas.

Maritza Paredes. Buenos días, Pablo. Gracias por acompañarnos en esta entrevista. Queremos conversar contigo acerca de tu reciente libro, próximo a publicarse en español, La Argentina transgénica. De la resistencia a la adaptación, una etnografía de las poblaciones campesinas. Nos interesa entender cómo tu trabajo con las poblaciones rurales expuestas a los efectos de cultivos genéticamente modificados, en este caso de la soja en Argentina, nos ayuda a analizar, desde otra perspectiva, los ciclos de movilización que produce la expansión de este tipo de economías de commodities, como lo vienen siendo los cultivos transgénicos. En tu trabajo, no solo buscas entender la movilización como consecuencia de esta expansión, sino que también has intentado comprender, como parte de estas respuestas, el proceso de desmovilización que ocurre así como sus impactos.

Entrevista realizada el 2 de abril de 2019.

Codirectora de Debates en Sociología. 
Me gustaría que nos expliques un poco más por qué es importante tomar en cuenta, dentro del ciclo de la movilización, también a los procesos de desmovilización, ya que, para muchos, en realidad, la ausencia de movilización implicaría simplemente que hay satisfacción con los procesos; sin embargo, creo que tú tratas de explicar que dicha ausencia implica algo más complejo que ello.

Pablo Lapegna. Muy buena pregunta. Me parece importante porque, como tú dices, siempre nos enfocamos en la protesta porque sale en los diarios y es lo más visible. Pero a mí lo que me interesaba, a partir del trabajo etnográfico, era comprender por qué el movimiento campesino, con el cual trabajé, dejaba de protestar, pese a que no aceptaban la situación en la que estaban, ni tampoco significaba que el movimiento desaparecía. Así, entendí que estudiar el proceso de desmovilización, desde una perspectiva sociológica, es importante, sobre todo, para aquellos a quienes nos interesan los movimientos sociales porque expande nuestras ideas y conceptos de cómo la gente resuelve sus problemas cotidianos. Los que trabajamos en esta área tendemos a mirar cómo la gente organiza una acción colectiva de protesta para resolver cierto problema o plantear públicamente una queja, pero, desde esta mirada, se nos escapan muchas veces todas las otras formas que las organizaciones, las personas y los grupos encuentran para resolver sus problemas o para plantear sus quejas de modos que, quizá, no son tan confrontacionales, pero que son igualmente importantes.

MP. Y también se pierde de vista que las protestas pueden ser intermitentes también, ¿no? A veces olvidamos que no es solo un ciclo de protesta y otro de movilización, sino que muchas veces la protesta está pensada para conseguir formas de negociación, y, luego, si no funcionan, se vuelve nuevamente a la protesta. Es sobre esta intermitencia que en la literatura tal vez encontramos menos estudios.

$P L$. Sí, y en esa intermitencia también quedan cosas. Como en la metáfora en inglés, «el mar que viene y luego se va, pero en ese retiro del mar, quedan cosas», eso pasa también con la protesta. La protesta deja una serie de enseñanzas. Quizá algunas cosas parecen novedosas cuando vemos su remergencia, pero es en esa remergencia donde se explica mucho sobre lo que pasó antes y lo que pasó en el medio. Por eso, creo que contribuyen mucho los métodos cualitativos o etnográficos, porque nos permiten acceder a esa vida de los movimientos sociales que no es la vida pública, sino la vida más cotidiana y más invisible. $\mathrm{Y}$, sobre eso, un aspecto que quiero agregar es la importancia que ese acceso cualitativo a los movimientos puede tener, pues permite ver la relación entre los líderes y los discursos públicos, y de los líderes intermedios y las bases, en sus interacciones más privadas o invisibles. 
MP. Sí. A eso quería llegar también porque, muchas veces, cuando pensamos lo cotidiano, estamos pensando en acompañar a la persona en todos los momentos de la vida diaria; pero, en realidad, cuando uno habla de la protesta, la movilización, todo eso implica lo cotidiano en un sentido mucho más profesional. Implica no solo estar, digamos, en la casa, tomando té con la persona, sino acompañándola a sus reuniones, a sus conferencias. O sea, no es siempre la imagen de lo micro, como el estudio de la persona en su mundo más íntimo, sino también en su mundo público local.

$P L$. Sí, y el mundo en cualquier momento es un mundo de reuniones, muchas veces permanentes. Pueden ser reuniones internas del movimiento, que son muy ricas para observar la interacción entre los líderes y las bases, y también entre líderes y potenciales bases: cómo se dialoga y cómo se habla. También, pueden ser reuniones externas, como en mi experiencia: entre el movimiento con el que yo trabajaba y otras organizaciones. Es interesante ver esas interacciones para observar cómo los líderes hablan de diferente forma dependiendo de su audiencia. No en una forma cínica, pero de un modo que explica mucho estas otras dinámicas de las que hablábamos: de la protesta pública, de la negociación, y de cómo el movimiento logra ciertos objetivos en formas que no son siempre confrontativas.

MP. Claro, y tal vez eso nos lleva a la segunda pregunta, porque, en estas interacciones múltiples, tú hablas en tu libro de una mirada multiescalar, donde los actores se relacionan en distintas escalas, y a mí me daba la impresión de que siempre había sido un desafío en la sociología estudiar los distintos niveles donde se ubica la realidad social.

Entonces, están esos libros clásicos sobre lo macro, donde en realidad estamos mirando las organizaciones e instituciones grandes, los sistemas, y, por otro lado, están estas miradas mucho más puntuales de los actores en el ámbito local. Pero tu libro trata de quebrar esa dicotomía y tratar de pensar en una relación entre lo micro y lo macro. Por eso quería preguntarte: ¿qué crees que esa aproximación aporta a la sociología y, sobre todo, a la sociología política?

$P L$. Bueno, es una discusión a la que yo llegué a través de la lectura de la geografía. Hay muchos geógrafos que tienen trabajos muy interesantes y valiosos para entender las escalas, por un lado, pero también la importancia de la articulación entre esas escalas. La sociología, como disciplina, tiene una historia ligada al Estadonación que siempre tuvo importancia. En las últimas décadas, con todo el auge del estudio sobre la globalización y luego la teoría sistema-mundo, también se prestaba atención a esa escala. Pero quizá hay poca atención a cómo se articulan estas diferentes escalas, que no debemos tomar como naturales: lo global, lo nacional, lo provincial, lo local o la localización, pero todas esas escalas y sus articulaciones 
son importantes. Desde la sociología política y de quienes estudiamos movimientos sociales es necesario tenerlas en cuenta, porque juegan un rol fundamental para los movimientos; especialmente, para aquellos que actúan en espacios localizados - que son la mayoría, diría yo- y tienen que actuar en un contexto local muy especifico, con actores muy cercanos, pero también porque el acceso a recursos y oportunidades políticas se ve constreñido por un contexto provincial, distrital o regional. Y luego está el nivel nacional, que también juega un rol muy importante y que también responde a tendencias globales.

El caso que yo estudio es un ejemplo de cómo los cambios que ha habido en la agricultura en América son globales, pero la forma en que esto se articula con lo nacional y con la localización es algo que los movimientos deben entender, negociar y adaptarse, porque muchas de esas escalas a menudo entran en conflicto y en tensión. La forma como los movimientos procesan esas múltiples escalas permite entender las trayectorias y lógicas de los movimientos.

MP. Claro. Y la globalización, por ejemplo, no solo llega a partir de los commodities o de la industria, sino también a través de los movimientos sociales mismos. Está el tema de Vía Campesina ${ }^{3}$, por ejemplo, que en realidad es un movimiento global. A veces los movimientos se articulan más allá de las fronteras, y eso implica también movimientos en otro tipo de escalas, independientemente o en paralelo, del capital trasnacional.

$P L$. Lo que mencionas es muy importante, porque lo global no es solo el capitalismo o la globalización de la agricultura en términos de las corporaciones: también abarca a las organizaciones sociales. Cuando haces trabajo de campo en ruralidades latinoamericanas, puedes estar en el medio de un paraje y escuchar términos que las organizaciones adoptaron a partir de su relación con Vía Campesina, por ejemplo, o en su participación en foros internacionales. Así, lo global puede ser muchas cosas. Es, también, el aspecto trasnacional de los movimientos, que da todo un lenguaje, una forma de entender procesos que permite a muchos movimientos y organizaciones ver mucho más allá de los horizontes más localizados.

MP. Sí, claro. Te quería preguntar también sobre la importancia que tiene en tu libro la relación entre los movimientos sociales y las organizaciones políticas, que también es todo un tema en la sociología política: cómo los movimientos sociales se relacionan con las organizaciones formales del Estado, etcétera. Una cosa interesante es que esa relación que planteas no está dada solo por intercambio, ya sea de

\footnotetext{
3 Movimiento internacional de campesinos, hombres y mujeres rurales, indígenas, y trabajadores agrícolas en todo el mundo. Tiene una representación de 200 millones de agricultores.
} 
política o de beneficios (dinero, por ejemplo), sino que también hablas de interrelaciones performativas mucho más subjetivas y discursivas. Me parece interesante que lo desarrolles un poco más.

$P L$. Lo que yo veía es algo que surgió claramente del trabajo de campo, concretamente, de ver cómo el gobierno, a diferentes escalas nuevamente, impulsaba lo que yo llamo acciones performativas, basándome en una serie de trabajos de lingüística. El título del libro del lingüista J.L. Austin puede resumir en una frase la idea que planteo en el libro: «cómo hacer cosas con palabras».

Yo les presté atención a funcionarios de nivel raso que visitaron las comunidades afectadas por los agroquímicos y escribieron informes muy favorables a las demandas de los campesinos y campesinas. Por ejemplo, entrevisté a un funcionario que tenía una afinidad muy fuerte y daba validez a las demandas de los campesinos en sus informes. Sin embargo, lo que me importaba comprender era cómo estas acciones de poner las demandas en palabras, en informes, en textos, tenía finalmente un efecto performativo, en el sentido de que estas palabras producían efectos en el mundo.

Así, hay actos que crean cosas con palabras. Por ejemplo, si yo tengo dos personas delante de mí y los declaro marido y mujer, estoy diciendo algo, pero esas palabras que digo tienen un efecto en el mundo, pues convierten a estas personas en un matrimonio. Ese es un ejemplo muy elemental, pero me interesaba ver cómo se trasladaba eso a la esfera política, y cómo los gobiernos también crean, en el caso argentino, por ejemplo, una comisión de estudios de los agroquímicos para generar una serie de reportes, investigaciones, comisiones que, más que resolver el problema de fondo, lo que hacen es dar la impresión de que algo se está haciendo. Y en esto, para ponernos también sociológicos, lo que me interesa, influenciado por las ideas de Irving Goffman sobre la presentación en la vida cotidiana, es destacar - pues a veces puede perderse de vista- esta presentación de la vida cotidiana, estas acciones performativas que, en un nivel, pueden tener un nivel de cinismo, pues muchas veces las autoridades "prestan atención» a las demandas solo para se calmen, pero, al mismo tiempo, no siempre es así. Por eso te daba el ejemplo de ese funcionario que fue a esta zona y escuchó a estos campesinos real y honestamente.

Me parece importante mantener esos dos aspectos de la acción performativa: por un lado, la acción performativa que con las palabras produce efectos en el mundo pero que puede tener un aspecto instrumental para lograr acallar las protestas, y por otro, la acción performativa que puede tener un aspecto realmente empático, afectivo y de identificación con las demandas y que no tiene ese cinismo, pero que, en última medida, contribuye de igual manera al mismo efecto de que las demandas se diluyan y se pase más a cuestiones de negociación y de acomodo de los efectos negativos y ya no a la confrontación, como en este caso de la soya en Argentina. 
MP. Sí, y es importante porque a veces confundimos este tipo de actos performativos con lo que tradicionalmente hemos llamado populismo, porque el populismo, de alguna manera, es una forma de relacionarte en donde haces promesas, pero no necesariamente esas acciones tienen un impacto más allá de lo electoral o del apoyo político. En ese caso, estamos hablando de la traducción, en realidad, de las palabras a documentos, a situaciones de negociación que, como tú dices, pueden llevar o no a ciertos resultados, pero que están basados en esos actos performativos.

$P L$. Pero también, siguiendo lo que dices, es importante remarcar que, en esas acciones performativas, muchas veces se pone en juego un reconocimiento de ciertos actores que no es menor. Tú mencionabas el populismo. Muchas veces tendemos como sociólogos a decir «bueno, eso es meramente discursivo», como si lo discursivo fuese algo menor, como si las palabras se las llevara el viento, lo que es cierto, y en el libro también hago una crítica fuerte a solo hablar y producir reportes sin realmente tratar de resolver los problemas de fondo; pero, al mismo tiempo, me parece que el acto de reconocer a ciertos actores o de reconocer a ciertos sectores de la sociedad no es menor, tampoco. O sea, cuando se habla del populismo, sean los Kirchner en Argentina, Chávez en Venezuela o quien se te ocurra, reconocer que la gente de los barrios en Caracas o lo que en Argentina históricamente Eva Perón llamó «los cabecitas negras» — que hoy pueden ser para Cristina Kirchner los movimientos campesinos - son actores válidos de la vida social, con organizaciones que tienen algo que contribuir a las políticas públicas, en este caso, agrarias. Sobre todo, eso que incluso se vuelve más claro el día de hoy, cuando, en muchos de nuestros países de América Latina, hay un giro a la derecha, como en el caso de Argentina con el gobierno de Macri, donde se están cerrando muchas de las oficinas y programas que tenían que ver con los pequeños productores o los campesinos. Pero también hay una falta de reconocimiento: no se reconoce a los campesinos, a los pueblos indígenas o a los pequeños productores como actores que tienen algo para contribuir a la vida agraria y la vida rural en Argentina. Y eso es importante.

$M P$ S Sí, y por eso el concepto de lo performativo es importante, porque, además, hay un reconocimiento que puede sobrevivir, pero también hay otro tipo de reconocimiento que luego se desvanece. Y, más aún, en un mundo globalizado, donde los estados están tan relacionados con leyes internacionales y pueden tener reconocimientos puramente formales. Muchos pueblos indígenas, por ejemplo, se quejan de la consulta previa y del IOT169, porque te da un reconocimiento que, como dices, "no es poca cosa». O sea, si consideras la historia de los pueblos indígenas, haber sido reconocidos por el Estado es una gran cosa, pero, al mismo tiempo, hay un conjunto de otros vacíos detrás de ese reconocimiento. Todo eso nos pone en una situación distinta hoy día. 
$P L$. Sí. Por eso, ese reconocimiento puede tomar diferentes formas. Y creo que es importante remarcar, como sociólogos interesados en la política, hasta qué medida ese reconocimiento discursivo-cultural, que no es irrelevante, se acompaña con la distribución del poder y de los recursos. ¿Quién tiene el poder de decisión sobre políticas publicas, quién tiene acceso al diseño de esas políticas públicas, y cómo los recursos son distribuidos en la sociedad? ¿Quién controla los recursos en el territorio? Todas esas cuestiones, por ejemplo. El reconocimiento puede ser un primer paso hacia eso, pero es muy difícil llegar hasta esta última parte de cuestiones de poder, de política y de recursos si primero no te reconocen como un actor válido y no reconocen tu identidad como importante.

MP. Muchas gracias por esta entrevista, Pablo.

$P L$. De nada, muchas gracias a ti. 